\title{
Reshaping the Concept of Substance: The Renegade Ockham
}

\author{
HANS KRAML, INNSBRUCK
}

The importance attributed to the concept of substance in the philosophy of the Latin Middle Ages may sometimes be exaggerated in retrospect. Substance is of crucial importance in the philosophies of Spinoza and John Locke, for instance, much later in history. Nevertheless, the importance given to substance in some philosophical movements is part of the medieval heritage up to our days. This, on the other hand, is a reaction to the neglect of the concept of substance in the Aristotelian sense within the tradition of modern natural sciences. The modern sciences as we know them developed out of the medieval learning. But the novelty of this type of science consisted in the definite refusal to answer questions about the essence of anything. The propagators of the new science tried to answer questions like how things influence one another and act upon another. Nobody knows, for instance, what gravity is, but it is well known and generally accepted that two bodies attract or, to say it less metaphorically, move towards one another directly proportionally to the product of their masses and indirectly proportionally to the square of their distance.

Evidently in a formula of this kind there is nothing said about what gravity is, there is only talk about how it works. The word "gravity" itself does not mean anything beyond the equation given. Gravity is just the acceleration in the movement of two bodies towards one another, if no additional force is present, nothing else. The word does not designate something in the bodies or in addition to the bodies and their movement. The word "gravity" is used for convenience, just because it has been used ever since Aristotle who took gravity to be an essential, substantial property of corporeal things.

The conceptual basis for the new outlook is a result of medieval discussions. These discussions had started at the beginning of the $13^{\text {th }}$ century with some important steps, one of which was the adoption of the explora- 
tions into Aristotle's concept of intellect by Muslim philosophers, especially Kindi and Farabi. Their respective treatises on the intellect had been translated soon into Latin. Albert, called the Great (1200-1280), was one of the first persons to present the new ideas on this theme in the Occident to the papal court at Viterbo in his solemn question "De intellectu et intelligibili". This is an obvious allusion to the title of Farabi's treatise, although I do not know yet, to which extent Albert was acquainted with Farabi's text. It is clear that he used Kindi's work. How ever this may be, it surely is the Arabic interpretation of Aristotle that made the ideas of this "first master" accessible and intelligible to Western philosophers.

A version of Farabi's general theory became the basic epistemological conception in the thirteenth century. Farabi's great achievement was an interpretation of the difficult passages in Aristotle's De Anima. This interpretation became the canonical point of reference in the following discussions from Ibn Sina via Ibn Rushd to Thomas Aquinas, the whole Medieval Latin tradition through Duns Scotus and William of Ockham and some other important, though less known thinkers like Theoderic of Freiberg down to the Renaissance and into the modern history of Western philosophy. The general structures of this theory still haunt even recent philosophers of mind.

Farabi held that for every intellectual being there is something called 'intellect' which is an ability to acquire knowledge or cognition of other things. This intellect is an intellect in potency ('aql b'il-quwa) because it is able to acquire knowledge without having it actually. But it is something existing in and possessed by intelligent beings. By contact with other things this potency is actualized; the intellect actually grasps something of a thing outside itself and thus becomes actual intellect ( 'aql b'il-fi $q$ ). This actualization is due to something that in itself is actualizing other things, namely the form of a thing. Forms generally actualize their own specific matter, but also the intellect in potency, whereby they act as forms in the way in which the intellect can accept forms. This sort of action is similar to that in which the form actualizes its own matter, but in this case the potential intellect serves as a kind of matter to produce pure forms in the mind. In this way the forms, otherwise constituting real things, act as intelligible forms. The forms actualizing the intellect in potency are stored in the intellect as pure forms acquired by that intellect, thus creating the acquired in- 
tellect. The forms stored in this way can consequently become active and thus produce knowledge of the things appearing in the surroundings of an intelligent being. In this way the intelligent being can recognize things it meets as things of a certain kind. At this stage the intellect has developed into the active intellect (intellectus agens, al- 'aql al-fa ' $\bar{a} l$ ). In case of the presence of something this active intellect can move the intellect, which in this respect is now passive, to realize the presence of something of a certain form, making a judgement about a singular case. This is the proper function of this passive (or possible) intellect. This is the manner in which an intelligent being acquires knowledge of the world it lives in.

An intelligent being, like a human person, has her proper, specific and perfective form actualizing herself as a person in this active intellect, which is part of the general, cosmic active intellect, the tenth emanation of the One, that actualizes matter outside the individual intellect and gives the same forms that are accepted by the intellect, to their proper matter.

This is obviously meant to be an interpretation of Aristotle's remarks in De Anima. And as far as I can see, and as far as the medieval commentators could see, it seems to me, this is the only interpretation that can make sense of Aristotle's cryptic remarks, and deliver a veritable theory of knowledge that can show how reality can be known as it really is. As the forms constituting the things are given to the things by the agent intellect and recognized by the intellect by the part through which it takes part in the cosmic agent intellect, it is granted that the intellect recognizes the things as they are. The forms constituting the things and the forms acquired by the intellect are, as forms, identical, although they produce in one case the real things, in the other case the recognition of these things as cases or exemplars of their very form. This guarantees that knowledge is exactly knowledge of the things as they are.

The theme of the intellect in Farabi's treatise is interwoven with questions of cosmology and ontology. This seems to be necessary in order to guarantee the equivalence or adequation between the world in its own matter and the world as it is intellectually grasped.

This may be the basis for the famous "definition" of truth as adequation of thing and intellect (adaequatio rei et intellectus), ascribed to Isaak Is- 
raeli ${ }^{1}$, but more closely fitting words found in Ibn Sina, ${ }^{2}$ who admits that he is indebted to Farabi.

In the course of the development of the Latin philosophy, Farabi's theory was remodelled by the theory of the multiplication of species, according to which the form of something is transmitted to the intellect. In the version of Roger Bacon these species are effects of the form of a thing by which the thing acts upon its surrounding medium. These effects are multiplied in the medium and thus transported to the senses and finally processed into intelligible species which constitute the forms as they are accessible to the intellect. The process of the multiplication of species in the medium is a strictly geometrical one. This is the basis of the perspectivist movement at the end of the thirteenth century. The cultural and scientific importance of this movement is considerable. Again it rests ultimately on Arabic influences, because it was the book on optics (Perspectiva - kitāb al-manāzir) of Abu Ali Muhammad ibn al Hasan ibn al Haitham (Alhacen in the Latin world) that was the basis for Bacon's theoretical achievements.

After Bacon, the theory of species was soon criticized by several thinkers, among them Peter John Olivi, Henry of Gent and others. ${ }^{3}$ The strongest criticism comes from William of Ockham (1285-1347) who entirely rejected the idea of species. ${ }^{4}$ In connection with this rejection Ockham developed his own epistemology that departed completely from the line of thought founded by Farabi. Together with this departure Ockham favoured a different interpretation of Aristotle's theory of substance and substantial form that gave up its cosmological foundation and led him to a different theory of truth. This theory says that a proposition is true if and only if the cases for which the subject term is introduced are identical with those cases for which the predicate term of the sentence is introduced according to the construction of the proposition. A negative proposition is true if the exemplars of the relevant terms are not identical. Everything depends on the introduction or imposition of the terms, either singular or universal. A positive proposition is true if the case or the cases brought into play by the sub-

\footnotetext{
${ }^{1}$ Isaac Israeli 1938, 322-323.

2 Ibn Sina 1977, 55.

${ }^{3}$ Tachau 1988.

${ }^{4}$ Ockham 1981, 268.
} 
ject term could be used to introduce the predicative term into the language in use.

If in our practical daily life we have to do with things, we gain intuitive knowledge of them. Partly we remember something of these things which enables us to repeat successfully certain actions concerning the thing in a different situation. Sometimes we may remember those actions successfully concerning other things that allow for the repetition of these actions and are in this sense similar to the other things. In order to cooperate with other beings we introduce signs to direct attention to things of importance in a certain context and to evoke the repetition of actions that were successful earlier. This part has to do with abstractive knowledge in Ockham's sense. It is by abstractive knowledge that we can remind ourselves and other people of things and that we can make plans about them even in their absence. The problem of reasoning about things in their absence was the main reason for John Duns Scotus to uphold the idea of intelligible species. For Ockham this is not necessary, because our ability to repeat operations and to learn routine activity in outer practice and in the realm of communication suffices to grant us the possibility of reasoning and planning.

According to Ockham what we grasp of the things with which we have to do in our life are not likenesses or representations or the forms of things in the way in which they can be grasped by the intellect, but just signs of the things. To speak of likenesses has only meaning where different things are compared, but not when a thing is taken notice of. In the intellect (or in the soul, as Ockham usually says) a natural sign is built for the thing that has come into the realm of intellectual activity. For purposes of human communication, a corporeal external item or event is used in order to signify to other participants what is at stake. The external-let's say linguistic-sign signifies to other persons the thing in question, not the natural sign held by the speaker or the impression or conception the speaker has. So, if we use our words in accordance with their proper function, we speak about the things outside of our mind, not about the signs we have in mind of those things. In order to be able to make other people understand what we are speaking about, we have to use those signs that are accessible to everybody, because they are external events, and are conventionally set for the things to which we want to direct the attention of our hearers. 
This imposition is possible at first only for things that are publicly accessible to virtually everybody. Generally, one can assume that this imposition is primarily possible for things that are easily picked out of their surroundings and that can be unambiguously identified by everybody who takes part in the situation. We may admit that these are the things usually taken to be first substances in the Aristotelian sense. This is at any rate widely assumed in the Middle Ages, and although I do not think that the acquisition of language starts with predication, I think that the introduction of predication necessarily makes use of the occurrence of these Aristotelian substances. As a matter of fact, it is much more difficult to learn the predication for qualities and other properties of things. The development of further devices for communication among people depends to some extent on elaborated parts of language. I don't want to go into more details here, although in the Middle Ages a great amount of the details were explored by the logicians at work then.

What now happens with Ockham is the following. According to him we acquire knowledge of the things in intuitive cognition by handling the things in our surroundings. Together with this we learn a language in order to coordinate our actions with those of others. Thus acquiring a language we learn to distinguish between cases that repeatedly occur and that have to be taken into account in every case of appearance, and other cases that may be less crucial. We may find ourselves with devices that are made to trace one and the same case at every moment of its appearance, and with devices that allow us to collect a greater number of exemplars that may appear on the scene together and at the same time. We thus have devices that refer to one and only one thing, and other devices that distinguish a number of things from other things that are in a given situation not traced individually. We thus have singular terms and general terms. But we always have to do with particular cases which we at one time can refer to by picking out just one singular case, at other times in a more general way, because we might be interested in something that has nothing to do with the individuality of the cases. So, if we need bricks to build a wall, for example, we surely need singular bricks because there are no universal bricks of which a wall could consist, but we are not interested in the individuality of the bricks, because within a certain range every brick can do the same job. Surely bricks are not good examples of Aristotelian substances, but we 
could tell a similar story about chickens, which in fact are Aristotelian substances.

What distinguishes Ockham from Farabi and his followers is that there is no talk of adequation or equivalence between the thing and the notion of it any more. The main interest of Farabi was, as I see it, to give an account of the possibility to grasp intellectually exactly what it is that makes the thing in question the thing it in fact is. It was the task of the intellect to grasp what is essential for the thing in independence of the intellect. This is by no means what Ockham is interested in, he does not even believe that such a task could be meaningful at all. We can say according to him that the species of the things, discussed widely in his time and rigorously rejected by him, are nothing but the forms of the things as they are considered in the intellect. In the course of the discussions at the beginning of the $14^{\text {th }}$ century, mainly at Oxford, it seems to me, sceptical positions had been taken into account because of the many awkward complications in the theory of species.

I think that Ockham somehow had the impression that the insertion of intermediaries, like species, in the process of cognition would ultimately lead to an unsolvable problem of scepticism. The actual reality of this problem can be seen in the position of Nicolaus of Autrecourt. It is less clear that Ockham suspected that a theory like Autrecourt's might take hold, but I think that his arguments show that he was aware of the possibility of such ideas and wanted to prevent their appearance. Ockham utterly rejected the theory of knowledge that was the result of the perspectivist account of perception. On its basis Nicolaus of Autrecourt could claim that not even Aristotle had ever had any real knowledge of a substance, because there is no possibility of deducing something like substances and the knowledge of that which is essential to a certain thing from sensual intuition and logic alone..$^{5}$.

Nicolaus would have claimed that in seeing something in front of you, you can never be sure that it is a substance you see, because the colours you perceive and logical considerations alone do not give you any certainty of something beyond sense-data and logic. Ockham's claim would have been that in seeing something at all you necessarily see that which causes

\footnotetext{
${ }^{5}$ Lappe 1908, 12*.
} 
your seeing of the object. So if you see some colours in front of you, you necessarily see something like, for instance, a horse in a meadow. Properly speaking you don't see the colours but that which is so coloured. You just have the impression of colours by which you see that which is so coloured. This is a remark on the grammar of "seeing". And if you see a horse, you see a substance, by definition. There is no problem of having sense impressions and the usual tools of logic in order to arrive at substances. You may have sense impressions, but some of them are of necessity impressions of something. The other possibility is that something like after images is at stake. These are just causal results of something involved in the process of perception, but they do not have anything to do with cognition and knowledge. Knowledge and causal influences on the sense-organs have to be distinguished at any rate. Ockham's arguments here may have to do with those of Peter Aureol. ${ }^{6}$ To me it seems that Ockham tried to rule out a special type of theory of cognition in order to avoid sceptical consequences. Nicolaus of Autrecourt is right if he claims that nobody, including Aristotle, could have derived with certainty the existence of a substance on the basis of bare sense data and formal logic alone. ${ }^{7}$ But it is far from obvious that one ought to operate with sense-data, and Ockham's intuitive knowledge is knowledge of the things, substances and qualities, in question, not knowledge of their species or of data of them. The things outside the mind or the soul are not represented to the soul by an intermediary, whatever it may be, but they are taken into account by human (or other intellectual) beings immediately by acquaintance, and what can be known about them is not more than what has to be taken into account by intelligently acting beings. In several branches of modern epistemology we find the idea of mental representation. Ockham's arguments are worth taking notice of, because they may at least help to clarify the status of such representations. The creation of intermediaries like species or data and so on would be the creation of parasitic entities, and such entities are ruled out by Ockham's razor, which thus is not so much a principle of parsimony than a parasiticide.

Ockham's position is directed against something that one could call essentialism. He insists on the existential priority of individuals of all kinds.

\footnotetext{
${ }^{6}$ Petrus Aureoli 1956, 698-690.

${ }^{7}$ Lappe 1908, 9*.
} 
Generalities and abstract entities for which individuality may be inapplicable, are products of the intellect or of the language. In this I see a development in the Occident that has a later-perhaps for several reasons laterparallel in Islamic philosophy. This parallel I see in some aspects of Mulla Sadra's philosophy. Nevertheless there are differences, and it may be of interest to find out the reasons for these differences in order to understand differences in philosophical attitude. These differences have to do with cultural differences. To trace them might mean to learn to understand them. Yet this makes it necessary to start discussions and confrontations of the different conceptions in the background of the philosophical developments in East and West. Despite the fact that Muslim and Western philosophies grew out of the same roots and were closely related at some stage in history, it is now difficult to bring the different ideas into contact. Lack of contact and even mutual isolation led to different vocabularies in addition to the problem that certain aspects of the different languages involved give rise to problems of interpretation from the beginning. To give an example: Is the concept of wahdat al-wujud comparable to the Scotist-Ockhamist concept of the univocity of being? One could maintain this, but the difficulty is that there is a difference between being and existence in Greek, Latin and some of the Western languages, like German, that is not easily expressed in Arabic, because the Arabic lacks a special word as sign for the simple act of predication, which is an important aspect of the concept of being in Western philosophy. Wujud, it seems to me, is closer to existence. Does this express a major difference? Has this an impact on philosophical considerations? This is only one of the themes for which a new dialogue between different developments in various cultures could prove very stimulating.

\section{REFERENCES}

Farabi 1938 Risalat fi'l- 'aql. Texte arabe integral, établi par Maurice Bouyges S.J., Beyrouth: Imprimerie catholique.

Avicenna 1977 Liber de prima philosophia, ed. Van Riet, Louvain-Leiden: Brill.

Isaac Israeli 1938 De Definitionibus, ed. Muckle 322 s, in: Archives d'histoire doctrinale et littéraire du Moyen âge 11, 299-340. 
Lappe, J. 1908 Nikolaus von Autrecourt. Seine Leben, seine Philosophie, seine Schriften, Münster: Aschendorff (BGPM 6-2).

Guillelmus de Ockham 1978 Expositio in libros artis logicae. Opera Philosophica II. Eds. E. Moody et al. St. Bonaventure, N.Y.: St. Bonaventure Univ.

- 1985 Expositio in libros Physicorum. Opera Philosophica IV-V. Eds. V. Richter, G. Leibold et al., St. Bonaventure, N.Y.: St. Bonaventure Univ.

- 1967-1979 Scriptum in librum primum sententiarum. Opera Theologica I-IV. Eds G. Gál et al., St. Bonaventure, N.Y.: St. Bonaventure Univ.

- 1981 Quaestiones in secundum librum Sententiarum. Reportatio. Opera Theologica V. Eds. F. Gál, R. Wood, St. Bonaventure, N.Y.: St. Bonaventure Univ.

- 1974 Summa Logicae. Eds. P.Boehner, G.Gál, S.Brown, Opera Philosophica I, St. Bonaventure, N.Y.: St. Bonaventure Univ.

Petrus Aureoli 1956 Scriptum super primum Sententiarum. Eds. E.M. Buytaert, St. Bonaventure, N.Y.: St. Bonaventure Univ.

Tachau, K. H. 1988 Vision and Certitude in the Age of Ockham. Optics, epistemology and the foundation of Semantics 1250-1345, Leiden: Brill (Studien und Texte zur Geistesgeschichte des Mittelalters 22). 